\title{
COMPETÊNCIAS EMPREENDEDORAS E SISTEMA DE RELAÇÕES SOCIAIS: A DINÂMICA DOS CONSTRUTOS NA DECISÃO DE EMPREENDER NOS SERVIÇOS DE FISIOTERAPIA ${ }^{1}$
}

\section{ENTERPRISING ABILITIES AND SOCIAL RECEPTION SYSTEM: THE DYNAMICS OF THE CONSTRUTOS IN THE DECISION TO UNDERTAKE IN THE FISIOTERAPIA SERVICES}

\author{
Daniel Jardim Pardini ${ }^{2}$ \\ Márcio Meira Brandão ${ }^{3}$ \\ Gustavo Quiroga Souki ${ }^{4}$
}

\begin{abstract}
Resumo: Este estudo analisa as competências empreendedoras e a rede de relações sociais no processo de decisão do exercício do empreender. Na literatura sobre empreendedorismo as pesquisas existentes focam em separado, ora no construto competências empreendedoras (DRUCKER, 1986; PAIVA et al, 2006), ora no construto relações sociais (GRANOVETER, 1985; VASCONCELOS 2005). A pesquisa contribui para a ampliação do debate teórico de como esses dois construtos são edificados e quais associações podem ser atribuídas a eles na abertura de um negócio. O modelo epistemológico proposto sugere analisar as competências e a influência das interações sociais nas perspectivas da percepção do ambiente e da ação estratégica. Utilizando a técnica de análise de conteúdo temática os fragmentos coletados das entrevistas com fisioterapeutas da Região Metropolitana de Belo Horizonte foram agrupados em sub-temas, núcleos temáticos e núcleos de sentidos associados aos dois construtos. Os resultados do trabalho demonstram que os profissionais da saúde agem de maneira intuitiva na concepção do próprio negócio e se abstêm de qualquer planejamento estratégico preliminar.
\end{abstract}

Palavras-chaves: Competências Empreendedoras; Relações sociais.

ABSTRACT: This study it analyzes the enterprising abilities and the net of social relations in the process of decision of the exercise of undertaking. In literature on intrapreneurship the existing research focus separately, however in constructs enterprising abilities (DRUCKER, 1986; PAIVA et al, 2006), however in constructs social relations (GRANOVETER, 1985; VASCONCELOS 2005). The research contributes for the magnifying of the theoretical debate of as these two constructs are built and which associations can be attributed they in the opening of a business. The considered epistemológico model suggests to analyze the abilities and the influence of the social interactions in the perspectives of the perception of the environment and the strategical action. Using the technique of thematic analysis of content the collected fragments of the interviews with physiotherapists of the Region Metropolitan of Belo Horizonte had been grouped in thematic sub-subjects, nucleus and nucleus of felt associates to the two constructs. The results of the work demonstrate that the professionals of the health act in intuitive way in the conception it proper business and if they abstain from any preliminary strategical planning.

Key-Words: Entrepreneurship Abilities; Social Relationship.

\footnotetext{
${ }^{2}$ FUMEC-Pardini@fumec.br

${ }^{3}$ FUMEC-Pardini@fumec.br

${ }^{4}$ FUMEC - Pardini@fumec.br
}

${ }^{1}$ Artigo apresentado no XXXI EnANPAD 2007 - Rio de Janeiro.

Artigo Recebido em 07.10.2008. Revisado por pares em 07.10.2008. Recomendado em 21.11.2008 por Denise

Del Pra Netto Machado (editora). Publicado em 08.12.2008.

Organização Responsável pelo periódico: Universidade regional de Blumenau - FURB.

Revista de Negócios, ISSN 1980-4431, Blumenau, v13, n. 1, p. 28 - 44, Janeiro/março 2008. 


\section{INTRODUÇÃO}

$\mathrm{Na}$ literatura de empreendedorismo a capacidade de visualização do ambiente e os sistemas de relações sociais são tratados como componentes das competências empreendedoras (FILION, 1991; BRUSH et. al, 2001; PAIVA JR. et al, 2006). Pouco se sabe, no entanto, como são construídas as habilidades que qualificam o empreendedor e de que maneira as relações sociais interferem na decisão pessoal de levar em frente à idealização de um projeto de trabalho. A concretização de um empreendimento visionário pode estar associada, tanto ao esforço próprio que independe da utilização mais efetiva de interações sociais, como da viabilização pela rede de contatos que o indivíduo dispõe.

As competências podem ser edificadas no processo de aprendizagem oferecido pelos cursos de formação educacional ou na própria experiência pessoal e profissional. Em todas essas situações as relações pessoais exercem influência na elaboração do negócio que se deseja implementar. Alguns estudos mostram que as esferas sociais - família, amigos, colegas de trabalho e de formação educacional - cumprem um importante papel na edificação e alavancagem de um negócio (BIRLEY, 1986; ALDRICH e ZIMMER, 1986; FILION, 1993). No entanto, são ainda poucos os estudos que buscam compreender essa dinâmica.

Para observar e analisar os impactos desses dois construtos na concepção de um empreendimento optou-se por estudar o setor de serviços físioterápicos na região metropolitana de Belo Horizonte. A opção pelo segmento de serviços da saúde remete à escassez de estudos destinados a conhecer o comportamento desses profissionais ao empreenderem na sua área de conhecimento. Pouco se conhece sobre as habilidades e redes sociais que condicionam a escolha do médico, do dentista ou do veterinário ao decidirem pelo negócio a ser empreendido. Em geral, o fisioterapeuta recém-formado depara-se com o dilema das diversas alternativas existentes: exercer a profissão em hospitais, clínicas, academias de ginásticas, clubes desportivos, centros de saúde, indústria, escola de formação superior ou mesmo inovar, ousar e abrir o próprio negócio. Nesse sentido, pretende-se responder à seguinte questão de pesquisa: Como as competências empreendedoras e os sistemas de relações influenciam na decisão de empreender do profissional fisioterapeuta?

A proposta da investigação visa contribuir para com o debate sobre a influência da formação das competências empreendedoras e do sistema de redes sociais nas decisões das atividades de negócio a serem empreendidas. A pesquisa pode vir a apontar atributos que perfazem o processo de escolha nos serviços de saúde, bem como, as competências e as relações sociais que interferem nessa decisão. A sessão seguinte trata das abordagens teóricas que amparam os dois construtos.

\section{COMPETÊNCIAS EMPREENDEDORAS E SISTEMAS DE RELAÇÕES SOCIAIS - PERSPECTIVAS TEÓRICAS}

A concepção de empreendedor utilizada neste estudo fundamenta-se nas perspectivas epistemológica comportamental e social e explora os atributos associados às competências empreendedoras e os sistemas de relações sociais utilizados na implementação de um negócio. Mais do que simplesmente ser proprietário de um negócio, o empreendedor é aquele que corre riscos, vislumbra oportunidades, antecipa-se em relação aos demais na consolidação de ações empreendedoras específicas, utiliza-se de fontes de informações preliminares e da rede de relações sociais na estruturação de suas atividades. Este tópico se divide em dois momentos: o arcabouço teórico que sustenta a manifestação das competências individuais empreendedoras e as teorias que amparam a estruturação e influência das redes sociais na geração e evolução de empreendimentos. 


\subsection{Competências individuais empreendedoras}

O conceito de competência vem sendo amplamente explorado nos últimos anos em discussões acadêmicas. Derivada do inglês competence, competência é definida como uma condição ou qualidade de suficiência de conhecimentos, habilidades ou sucesso (WEBSTER, 1999). O Moderno Dicionário da Língua Portuguesa Michaelis (2004) revela que competência é a faculdade para apreciar e resolver qualquer assunto. Competência pode também ser concebida como uma característica que engloba diferentes traços de personalidade, habilidades e conhecimentos, influenciados pela experiência, capacitação, educação, história familiar e aspectos demográficos peculiares à pessoa (KETS DE VRIES, 1996; MAN e LAU, 2000).

Para alguns autores, as competências não se limitam apenas ao estoque de conhecimentos teóricos e empíricos do indivíduo; diz respeito à ação de colocar em prática o conhecimento em uma determinada situação (FLEURY e FLEURY, 2004) e às capacidades de transferência de aprendizagem e adaptação a um novo cenário (PARDINI, 2005). O especialista competente seria aquele em que se reconhece particular habilidade em determinado campo de conhecimento, o que marca a ruptura entre aquele que a detém e os que não a possuem ou a têm de forma incompleta (LUZ, 2003).

Na literatura sobre empreendedorismo uma gama de características é encontrada para definir o perfil do empreendedor. No entanto, o que se percebe é uma miscelânea de significados apresentados de maneira ampla e variada. $\mathrm{Na}$ tentativa de estruturar as perspectivas conceituais existentes, classificamos as competências empreendedoras em duas dimensões: aquelas associadas à visão do ambiente dos negócios e aquelas relativas à colocar em prática as ações idealizadas.

\subsubsection{Competências associadas à visão do ambiente}

Entre as competências do empreendedor, destaca-se a capacidade de visualizar o ambiente que antecede e ampara o processo de decisão. Filion (1991) classifica a visão empreendedora em três categorias: visão emergente, visão central e visão complementar. A visão emergente refere-se ao desenvolvimento de produtos e serviços que apresentem potencial de mercado. A visão central seria decorrente do resultado de uma ou mais visões emergentes, podendo ser originada de uma visualização externa - faixa de mercado a ser ocupada por um produto ou serviço - e outras internas - que indicam os caminhos para viabilizar o negócio. A visão complementar estaria associada às atividades gerenciais necessárias para dar suporte à visão central.

De acordo com Filion (1999a) os empreendedores têm visões, cuja elaboração demanda tempo, comprometimento e imaginação sobre o objetivo a ser perseguido e os caminhos necessários para realizá-lo. Diferentemente dos gerentes e executivos tradicionais, que normalmente utilizam habilidades administrativas para atingir metas a partir dos recursos disponíveis na estrutura organizacional (FILION, 1999b), o empreendedor está voltado para a definição de contextos e a organização dos recursos necessários para fazer frente às oportunidades e ameaças ambientais (DORNELLAS, 2005). No decorrer desse processo pode ser desenvolvida a competência de oportunidade, a competência de utilização de fontes de informações para o conhecimento prévio do negócio e a competência de assumir riscos.

\subsubsection{Competência de Oportunidade}


Uma das principais fontes de elucidação da visão empreendedora são as oportunidades presentes no ambiente dos negócios (DESCHAMPS e NAYAK, 1996). Paiva Jr., Leão e Mello (2003) classificam o desenvolvimento da capacidade de se antecipar ao mercado e estruturar ações para concretizar um determinado empreendimento como competência de oportunidade. A oportunidade é uma idéia que está vinculada a um produto ou serviço que agrega valor ao consumidor, seja por meio da inovação ou da diferenciação.

Kuratko e Hodgetts (2004) tratam a oportunidade como uma das Escolas do Pensamento Empreendedor. Para os autores, as pesquisas sobre as fontes de idéias, o desenvolvimento de conceitos e a implementação das oportunidades formam importantes áreas de interesse dessa Escola. No desvendar de potenciais idéias de negócios a criatividade e a conscientização para o mercado são vistas como essenciais. A identificação de uma oportunidade inicia-se quando o indivíduo identifica e entende um determinado tipo de negócio com potencialidade de ser explorado. Percebida a oportunidade ele focaliza o nicho de negócio, aprofunda o conhecimento na sua dinâmica de funcionamento, elabora cenários para por em prática o negócio e, por fim, planeja a execução da idéia (Fillion, 1991). Para compreender melhor o setor de atuação do negócio pode-se fazer uso de habilidades focadas no estudo detalhado do empreendimento.

\subsubsection{Competência de utilizar fontes preliminares de informações sobre o negócio}

A competência de antecipar-se ao negócio por meio do uso de informações preliminares auxilia no desenvolvimento da competência de visualização do ambiente de negócios. Uma tarefa crítica antes de iniciar um negócio é analisar e avaliar a viabilidade da idéia do produto ou serviço. Isso é feito por meio de levantamentos qualitativos e quantitativos da viabilidade do empreendimento. O processo analítico consiste na utilização de fontes de informações necessárias à percepção das tendências emergentes no ambiente e do conhecimento antecipado da oportunidade alvo (KETS DE VRIES, 1996). Três fontes de dados amparam a análise que antecipa a ação empreendedora: publicações acadêmicas e populares, observações diretas da prática de empreendedores e a participação em seminários sobre a temática (KURATKO e HODGETTS, 2004).

A construção de uma abordagem sobre a viabilização do negócio pode incorporar fatores externos que auxiliam na compreensão preliminar do empreendimento. Compreender as necessidades dos consumidores, por exemplo, constitui-se em uma importante base de informação para o entendimento prévio do ambiente de negócios. Kuratko e Hodgetts (2004) propõem outras áreas para a análise da viabilidade de uma nova idéia: $a$ ) técnica: que analisa o potencial do produto ou serviço; $b$ ) de mercado: que pesquisa as oportunidades do ambiente mercadológico; c) financeira: que examina os recursos de capitais disponíveis e necessários e; d) de competitividade que identifica as características dos principais concorrentes.

\subsubsection{Competência de assumir riscos}

O terceiro componente da competência de visualizar o ambiente refere-se à habilidade de saber lidar com situações de risco. Paiva Jr. et. al. (2003) incorporam a avaliação do risco como uma competência conceitual do empreendedor. A capacidade de enxergar o todo permite ao detentor dessa competência conhecer o impacto de suas decisões no negócio. São indivíduos capazes de buscar alternativas por meio de percepções concebidas por ângulos diversos sobre determinada oportunidade. O desvendar dos possíveis caminhos que antecedem ao processo decisório auxilia a contornar os riscos da empreitada. Liles (1974:14) identifica diferentes tipos de riscos encontrados pelos empreendedores: 
a) Riscos financeiros: em grande parte dos novos empreendimentos os indivíduos colocam uma significativa porção de seus recursos; capital que será perdido no caso de falhas do negócio.

b) Riscos da carreira: um dos dilemas para se tornar empreendedor está associado ao momento apropriado para abandonar o emprego e se aventurar em um novo negócio.

c) Risco social e familiar: em geral empreendedores que são casados ou constituíram famílias acabam expondo seus familiares ao se arriscarem em um novo empreendimento.

d) Riscos de natureza física: o insucesso de um negócio pode implicar em impactos de ordem física e psicológica.

\subsubsection{Competências associadas à ação estratégica}

Para colocar o produto ou serviço concebido no plano visionário em ação, o empreendedor faz uso de competências associadas à implementação de estratégias. Paiva Jr. et. al (2006) evidenciam a dimensão de competências estratégicas como aquelas ações escolhidas na implementação do planejamento estratégico. A abordagem da formulação estratégica na teoria empreendedora enfatiza o processo de planejamento e execução bemsucedido do empreendimento (LYLES, BAIRD, ORRIS e KURATKO, 1993).

Degen (1989); Drucker (1986); Bernardi (2003) e Bergamini (1997) relatam que a criatividade, a motivação e a inovação são essenciais para a concretização da visão empreendedora. A criatividade consiste na geração de idéias que resultam no aprimoramento da eficiência e da eficácia de um sistema (WHITING, 1988). Dois importantes elementos afetam a criatividade: os processos e as pessoas. Os processos são orientados para o objetivo e estruturados para solucionar problemas. As pessoas constituem os recursos humanos que determinam as soluções. É por meio da criatividade que o empreendedor viabiliza a idéia originária da análise do potencial do mercado. Ela é resultante do monitoramento incansável dos produtos e serviços demandados pelo mercado, da identificação de potenciais clientes e do acompanhamento de possíveis concorrentes (DEGEN, 1989) do negócio a ser colocado em prática.

A motivação se traduz no segundo fator para a consolidação da idéia. Entre as principais razões que levam os indivíduos a se sentirem motivados, Bernardi (2003) enumera: 1) a necessidade de realização, 2) a implementação de propostas 3) a fuga da rotina profissional, 4) a assunção de maiores responsabilidades e riscos, 5) o reconhecimento de capacidades adquiridas, 6) o aumento da renda, 7) o status e o controle da qualidade de vida. Dentro dessa mesma perspectiva comportamentalista, os estudos realizados por Benedetti, Guardani, Carvalho, Daros e Bizzarri (2005) indicam que alguns empreendedores encontram motivação a partir das necessidades de auto-realização. A orientação para a realização é fundamentada na busca de ações projetadas para a construção de um projeto de vida. As recompensas alcançadas com a execução dos planos estabelecidos reforça a auto-confiança em realizar mais ações e incentiva a busca por novas possibilidades de realização.

O terceiro componente necessário para materializar a visão empreendedora está associado a estabelecer os meios que viabilizem o exercício da inovação em um determinado negócio. Drucker (1986) revela que a inovação é a atividade central do empreendedor. Inovações ocorrem por idéias originadas da observação, da percepção e da criatividade. Consolidam-se da pesquisa consciente em torno das oportunidades disponíveis no mercado. No desenvolvimento da habilidade de criação, a racionalidade, as rotinas e o uso de antigos padrões e costumes podem impedir ou dificultar a viabilização de capacidades inovadoras (BERNARDI, 2003). 


\section{SISTEMAS DE RELAÇÕES - AS REDES SOCIAIS E A INFLUÊNCIA NA ATIVIDADE EMPREENDEDORA}

Para Granovetter $(1985,1992)$ a relação de um indivíduo com o ambiente de negócios está amparada por dois tipos de inserção social: a relacional - que envolve as relações entre duas pessoas, entre pessoas e organizações ou entre organizações - e a estrutural que se refere à estrutura de rede social que determinado indivíduo está inserido. No caso deste estudo o objetivo é desvendar a influência do sistema de relação social na definição do profissional de saúde ao optar pelo destino de suas atividades.

As inserções sociais, relacionais e estruturais desempenham importantes papéis na geração de confiança no contexto das relações de negócios entre pessoas e organizações. Nesse ponto, as construções sociais influenciam as ações dos indivíduos inseridos na rede de relacionamentos pessoais (GRANOVETTER, 1985, 1992). Alguns estudos têm analisado a inserção de atores sociais, firmas e indivíduos em um determinado meio social (JOHANNISSON, 1998). Outros autores têm estudado os vários arranjos de redes sociais realizados entre empresas e pessoas (DACIN, VENTRESCA E BEAL, 1999). Os interrelacionamentos sociais são utilizados, tanto como forma de acesso aos recursos inexistentes para o desenvolvimento do negócio (OSTGAARD E BIRLEY, 1994), como para fonte de informações úteis, confiáveis e exclusivas usadas para captar novas oportunidades de mercado.

Diante da oportunidade de criação de novos negócios os indivíduos recorrem às pessoas do seu relacionamento próximo tais como familiares, amigos e colegas de trabalho para obterem os recursos necessários à viabilização da idéia (BIRLEY, 1986; ALDRICH e ZIMMER, 1986; VASCONCELOS, 2005). Esses contatos objetivam o apoio de idéias, aconselhamentos e suporte social e emocional para a consolidação do empreendimento (JOHANNISSON,1998; BARNIR e SMITH, 2002). Larson, (1991) e (1992) sugere que a história e as experiências vividas pelo indivíduo são de extrema importância na identificação da rede de relacionamentos que dará suporte nessa etapa.

Neste ponto, a tipologia de relações sociais de Filion (1991) auxilia no mapeamento das pessoas que podem interagir e participar do negócio alvo. O pesquisador propõe três níveis de relações sociais: primárias, secundárias e terciárias. As relações primárias envolvem os familiares e as pessoas mais próximas do relacionamento e estão associadas a diversos tipos de envolvimento exercido pela pessoa. Abrangem ligações tanto afetivas como intelectuais, esportivas e de lazer, influenciando o conceito de si do futuro empreendedor. As secundárias englobam amizades e conhecimentos ligados a uma atividade específica como clube social, atividade religiosa, trabalho ou política. As terciárias não são necessariamente relações entre pessoas, mas contatos com um campo de interesse. Acontecem por intermédio de cursos, viagens, exposições industriais, feiras e congressos (FILION, 1991).

O trabalho de Van Gigch (1987) também pode ser considerado como referência para se entender a importância dos sistemas de relações na construção da visão empreendedora. Para os autores a família é considerada o fundamento básico do sistema de relações do empreendedor. Valores e comportamentos absorvidos no seio familiar muitas vezes influenciam na sedimentação da visão de negócio que o indivíduo pretende desenvolver.

\section{O CAMINHO METODOLÓGICO}

$\mathrm{O}$ estudo aqui apresentado tem como objetivo analisar as competências empreendedoras e as redes de relações sociais que influenciam na escolha do fisioterapeuta sobre o tipo de negócio ou atividade a ser desenvolvido. A metodologia pode ser classificada 
como empírica descritiva, na medida em que se deseja colher dados de natureza subjetiva que subsidiem a interpretação dos dois construtos em foco.

$\mathrm{Na}$ seleção da unidade de análise definiu-se um escopo de entrevistados que abarcassem quatro situações distintas do exercício da atividade fisioterápica. Tendo como referência a classificação do GEM - Global Entrepreuneurship Monitor (2006) foi selecionado os seguintes tipos de profissionais:

1. Iniciais Nascentes - aqueles que geraram alguma remuneração e atuam no negócio há menos de três meses,

2. Iniciais Novos - aqueles que geraram remuneração e estão à frente do negócio há mais de três meses e menos que 42 meses.

3. Estabelecidos - aqueles que estão à frente dos empreendimentos há mais de 42 meses.

4. Outros - prestadores de serviços ou autônomos.

A divisão nessas quatro categorias atende ao entendimento de se visualizar diversas dimensões associadas à situação diferenciada do profissional de saúde no momento atual. A intenção foi analisar também se a influência das competências e dos sistemas de relações pode estar relacionada ao estágio profissional do fisioterapeuta. Assim, o prestador de serviços de saúde que empreende não necessariamente é proprietário de um pequeno negócio. Refere-se àquele que cria, inova e se destaca em sua atividade fisioterápica.

Por meio da técnica de "bola de neve" os fisioterapeutas foram sendo selecionados utilizando de indicações dos entrevistados. Ao final da entrevista o depoente indicava um profissional que considerava referência na área de fisioterapia na Região Metropolitana de Belo Horizonte, até atingir o ponto de redundância. Por fim, foram entrevistados o total de 23 sujeitos sendo: dois Iniciais Nascentes, 06 Iniciais Novos, 6 Estabelecidos e 9 Outros (07 professores, 01 aposentado e 01 administrador de clínica).

No tratamento dos dados foi utilizada a Análise Temática, uma das ferramentas da análise clássica de conteúdo. Segundo Bardin (1979: 105), o tema é a unidade de significação que emerge naturalmente de um texto analisado, conforme critérios relativos à teoria que serve de guia à leitura. Fazer uma análise temática consiste em descobrir os "Núcleos de Sentido" que compõem uma comunicação cuja presença ou freqüência signifiquem alguma coisa para o objetivo analítico visado (MINAYO, 2006).

A Análise Temática dos dados consistiu das seguintes etapas:

a) Transcrição e revisão dos relatos dos entrevistados.

b) Leitura exaustiva desse material deixando-se impregnar pelo seu conteúdo.

c) Agregação dos dados dos conteúdos das entrevistas nas perspectivas dos construtos competências empreendedoras e sistemas de relações sociais.

d) Identificação dos núcleos temáticos e núcleos de sentido dos dois construtos

e) Interpretação dos significados desses núcleos.

f) Tratamento e análise dos resultados obtidos e interpretação.

\section{COMPETÊNCIAS EMPREENDEDORAS E SISTEMAS DE RELAÇÕES SOCIAIS NOS SERVIÇOS DE FISIOTERAPIA}

$\mathrm{Na}$ análise dos depoimentos os fragmentos gerados nas entrevistas foram estruturados em três núcleos temáticos: competências associadas à visão do ambiente, competências associadas à ação estratégica e fontes de influência social. Desses três temas identificou-se os núcleos de sentido que compõem a comunicação dos entrevistados e procedeu-se a análise das significações presentes nos discursos. 


\subsection{Competências empreendedoras no exercício da fisioterapia}

Para entender as competências necessárias para a atuação no segmento de serviços de fisioterapia os depoimentos foram agrupados em dois temas: as competências associadas à visão do negócio e aquelas condizentes com a ação de empreender.

\subsubsection{Competências da visão ambiental do negócio fisioterápico}

Três tipos de competências manifestadas referem-se à habilidade perceptiva de visualizar o ambiente de negócio: competências de oportunidade, competências de utilizar fontes preliminares de informações e competências de assumir riscos.

Pelos depoimentos é possível constatar que as competências do fisioterapeuta de enxergar oportunidades de negócios são oriundas do próprio período de formação acadêmica, da experiência profissional ou de outras demandas identificadas no ambiente de serviços fisioterápicos. Na etapa de formação, a identificação de especialidades profissionais ainda não exploradas no mercado se traduz em uma fonte de oportunidades. Da mesma maneira, a chance de absorver habilidades administrativas em empregos anteriores ilustra o quadro da estruturação de uma oportunidade advinda da possibilidade de ter convivido com atividades gerenciais. O depoimento abaixo ilustra essa situação:

\footnotetext{
"[...] comecei a montar a clínica na coragem, com a experiência que eu tive do Belo Horizonte [referindo-se ao hospital que trabalhou]. Quer dizer, sabia tudo, sabia onde tinha aparelho, sabia preço de tudo. Nunca tive medo de abrir. O que eu mais sei numa clínica é fazer cobrança, como marcar horário, como marcar consulta, esse aspecto que fisioterapeuta não sabe. Eu sabia, esse foi o meu diferencial" (Estabelecido 03).
}

O fato de atuar no negócio, de ter tido uma experiência anterior, mesmo como empregado, permitiu ao entrevistado a aquisição de conhecimentos que o auxiliou posteriormente no gerenciamento do empreendimento. Os propósitos da estruturação do negócio no campo fisioterápico derivam também de oportunidades relacionadas à demanda do mercado, em especial, das organizações diretamente envolvidas com os serviços de saúde e da necessidade de atender nichos específicos. As narrativas de fisioterapeutas estabelecidos no negócio há mais de 42 meses registram o desenvolvimento dessas competências de oportunidade:

\footnotetext{
“A gente sentiu essa demanda assim de ter um espaço maior e do lado do hospital. Tinha uma demanda muito grande de reabilitação e alguns casos estavam sendo encaminhados para mim. Então absorveu também, não só a demanda do hospital, como a demanda da clínica" (Estabelecido 02).

"O que mais me motivou a comprar o serviço foi justamente esta questão de um serviço dentro de uma academia. De uma academia que você tinha um fluxo de 300 , 400 pessoas lá dentro. Isso mobilizava a gente a trabalhar, a comprar o setor. Porque você tinha uma rotatividade de pessoas dentro da academia, então era mais fácil da gente poder fidelizar o cliente" (Estabelecido 06).
}

As oportunidades no segmento de fisioterapia manifestadas pelos entrevistados referem-se às competências em perceber as necessidades de determinadas organizações (hospitais e academias de ginástica) que necessitam do serviço e às demandas específicas de um determinado segmento (pacientes de reabilitação da mão e atletas). Não necessariamente a oferta do serviço pressupõe a abertura de um negócio. As oportunidades percebidas envolvem também o arranjo de parcerias com outras empresas (hospital e academia). 
Os fragmentos extraídos das entrevistas apontam a ausência do desenvolvimento de competências associadas ao estudo de informações preliminares que justifiquem a implementação do negócio. A grande maioria dos fisioterapeutas não fez uso de recursos de planejamento para orientar a decisão sobre os tipos de negócios escolhidos. Os relatos abaixo mostram algumas manifestações de desconsideração pelo conhecimento prévio do negócio:

\footnotetext{
"A gente ia montando, a gente ia vendo a possibilidade e ia fazendo. A gente não fez estudo de mercado não. Foi mais uma conseqüência da necessidade de expandir, tinha uma clientela boa, um volume de pacientes bons, então a gente viu a necessidade de expandir, aí expandiu" (Inicial Novo 06).

"Não fiz nenhuma avaliação, não procurei saber. Já entrei com ela [sócia] $50 \%$ a $50 \%$, não coloquei maldade, não conhecia ela bem, coloquei ela como administradora da minha empresa e já coloquei como sócia de 50\%, 50\% exatamente por não ter feito esse planejamento que deveria ter sido feito né?" (Estabelecido 01).
}

Os depoimentos demonstram que os entrevistados agiram com a intuição ao decidirem pelo tipo de empreendimento. A elaboração de planos de negócios é ainda hoje descartada por aqueles que estão começando os seus empreendimentos (caso do Inicial 06). $\mathrm{O}$ compartilhamento do negócio com outro sócio da área de gestão, situação ilustrada pelo Estabelecido 01, também é utilizado como justificativa para a ausência de um planejamento mais detalhado. Nenhum dos entrevistados optou por um detalhamento mais complexo que envolvesse as análises de viabilidade financeira, organizacional ou competitiva sugeridas por Kuratko e Hodgetts (2004). Muitas vezes a falta de tempo ou de informações suficientes para antever possíveis cenários do negócio acaba levando o dirigente a ir se adaptando e solucionando os problemas do empreendimento no decorrer de sua implementação.

Da mesma maneira o exercício da competência moderadora do risco não aparece nas falas dos fisioterapeutas. As decisões sobre a abertura dos negócios foram conduzidas "na cara e na coragem", "no tapa" e "no peito". Essa característica de optar por correr o risco, de aprender por meio da tentativa e erro ao iniciar as atividades do negócio, predominou na maioria dos depoimentos.

\subsubsection{Competências da ação estratégica nos serviços de fisioterapia}

A transformação da idéia em prática é realizada por meio de processos criativos que auxiliam na materialização do negócio proposto. Em geral, a concretização da visualização do negócio é procedida de estratégias de inovação e diferenciação. Colocar em ação algo ainda não testado no mercado, por exemplo, representa a manifestação de uma competência de inovação estratégica. No segmento em estudo, o pioneirismo na atividade fisioterápica, antes exercida por profissionais da medicina física, é ressaltado no depoimento que segue:

“[...] a fisioterapia em 1985, 1986 estava na mão de fisiatras, tinha muito poucos fisioterapeutas com clínica constituída, com nome. A maioria das clínicas era só de médicos. Não se dava uma atenção aos fisioterapeutas, ou seja, a atividade fim era medicina, não era a reabilitação. A gente criou a clínica com a atividade fím de reabilitação, então dai o diferencial nosso em relação às outras clínicas do mercado" (Estabelecido 04).

Não necessariamente o empreendedor é o inventor (KURATKO e HODGETTS, 2004). A pessoa que aprimora ou busca um nicho ainda desconhecido no negócio aumenta as chances de acertar com a implantação da idéia. Uma outra maneira de diferenciar o serviço 
está no desvendar demandas associadas à atividade central. O desenvolvimento dessa habilidade é reforçado pelo entrevistado abaixo:

“[...] além dos atendimentos específicos, como hidroterapia para gestante, hoje nós estamos ministrando cursos para profissionais como se fosse até uma consultoria nas áreas afins. Hoje existe curso e até consultoria na área de fisioterapia aplicada a ginecologia, obstetrícia, na odonto pediatria, na odontologia e na enfermagem" (Estabelecido 05).

Na montagem do negócio, a criatividade se traduz em diferencial ao ser utilizado como atividade original não explorada pelos concorrentes. $\mathrm{O}$ relato seguinte descreve uma estratégia utilizada por uma depoente para oferecer um diferencial no serviço prestado:

"Eu imaginava ter uma clínica, trabalhar num lugar legal, assim de preferência parecendo uma sala de artes, eu sempre gostei de mudar as coisas. De repente, o lugar que eu estava atendendo virava brinquedoteca, cheio de coisa. [...] eu sempre levava alguma coisa da terapia ocupacional para o setor de fisioterapia para ver se a coisa ficava um pouco mais interativa" (Estabelecido 02).

A estrutura física do empreendimento que receberá a idéia proposta para o empreendimento, quando trabalhada de forma diferenciada, torna-se uma atratividade para a clientela. Saber manter o ambiente de trabalho em condições propícias ao exercício da atividade fisioterápica ajuda na empreitada de garantir boas condições para o serviço de trabalho e satisfação do cliente. Alguns depoentes relatam a importância de observar a qualidade e a manutenção constante do local de atendimento na área de saúde:

\footnotetext{
"Conhecendo as outras instituições nós procuramos inovar de alguma forma. Primeiro a questão do ambiente: é uma casa, é uma clínica, um local de residência, então esse ambiente tem que se aproximar do máximo. Ele tem que ser um lugar onde as pessoas chegam e elas se sintam bem, a gente procura manter um ambiente que ele é diferenciado do que existe no mercado" (Inicial Novo 01).
}

“[...] é uma clínica que está extremamente moderna, ela está toda bem equipada. Todo ano eu reformo ela, todo ano os equipamentos são melhorados, ou são limpos, ou são reformados, ou são trocados. Cada ano tem um objetivo: tem ano que é melhorar o aspecto da piscina, então melhora tudo, troca os azulejos, troca tudo" (Estabelecido 03).

Manutenção e aprimoramento do ambiente organizacional constituem-se em competências de execução estratégica importantes para a viabilização da visão empreendedora. Assim como os recursos físicos, os recursos humanos compõem os elementos estratégicos do empreendimento. No segmento fisioterápico as competências associadas à capacitação de pessoal são fundamentais para o bom funcionamento dos serviços. $\mathrm{O}$ diferencial da prestação do serviço de fisioterapia muitas vezes envolve o uso de profissionais de especialidades diversas. A habilidade demandada corresponde então em saber aproveitar as fronteiras existentes com outras áreas da saúde e alocar esses funcionários na função correta. A narrativa a seguir revela algumas competências empregadas para capacitar recursos humanos e habilitá-los a atenderem pacientes:

“[...] fazemos uma reunião semanal com as cuidadoras. Elas discutem os pontos que elas têm dúvidas, as dificuldades, tanto do cuidado, como da relação com esses idosos. Isso eu sei que não tem em outras clínicas. É um ponto que eu mantenho: essa capacitação dos funcionários. Nós temos a profissional da terapia ocupacional e a estagiária. A estagiária só está presente quando a profissional está também, então ela faz grupo de culinária, grupo de memória ai depois de três meses muda esse 
grupo, ai faz outro tipo de oficina. Uma coisa que eu acho que é importante é o atendimento externo, o acompanhamento externo. A gente tem pelo menos uma vez por mês um teatro, um jantar fora, um baile" (Inicial Novo 01).

Os diferenciais apresentados dizem respeito aos investimentos em especialização e modelos de relacionamento. Na prestação de serviços, as técnicas envolvem atividades criativas destinadas a atrair e acolher públicos específicos (pessoas da terceira idade) O papel do estagiário na atividade fisioterápica também é ressaltado no depoimento. Em uma outra entrevista um fisioterapeuta faz menção à não utilização de estagiários como diferencial na prestação de serviços da clínica. Nesse caso as justificativas remetem ao foco no atendimento prestado por profissionais experientes. Por outro lado, no relato acima prevalece a preocupação em preservar a função de aprendizagem que o estágio representa.

Entre os entrevistados, o grupo de pessoas que atuam como autônomos também utilizam estratégias para exercer de maneira empreendedora suas atividades profissionais. A qualificação e a permanente atualização de conhecimentos são frisadas como competências a serem desenvolvidas pelos profissionais que atuam em instituições de ensino superior:

\footnotetext{
"Eu sempre participo de Congresso nas áreas, como ouvinte e mandando trabalho também. Como eu dou aula fica muito mais fácil de mandar um volume maior de trabalhos, porque eu tenho os trabalhos de conclusão de curso. Isso é uma coisa que gera uma certa produção. Nas extensões também eu tenho uma produção dos Congressos, porque tenho pessoas, eu tenho uma equipe que trabalha comigo, então a gente tem um volume razoável de trabalhos em eventos" (Professor 01).

"[...] eu ando fazendo alguns cursos, não só curso de atuação na área da fisioterapia. $\mathrm{Eu}$ ando estudando um pouco sobre metodologia do ensino superior, eu ando estudando um pouco do porque da mudança do perfil do aluno principalmente das escolas particulares. Ando estudando o que eu posso fazer com a minha didática para que eu possa melhorar a forma de passar a informação, para facilitar o aprendizado desse aluno" (Professor 05).
}

As competências associadas à ação estratégica no segmento fisioterápico funcionam como meios para que o empreendedor consolide a visão idealizada para o negócio, seja diferenciando-se em relação ao serviço prestado ou inovando em termos dos processos de aprendizagem repassados a futuros fisioterapeutas. As inovações envolvem o pioneirismo no exercício da profissão e na exploração de nichos não existentes na prestação do serviço. Os diferenciais incorporam novas modalidades de atendimento e o uso da criatividade para constituir a estrutura do negócio em termos das instalações, tecnologia e formas de acolhimento do paciente. Na seção seguinte são abordadas as influências das relações sociais na concepção e implantação de empreendimentos de serviços de fisioterapia.

\subsection{Sistemas de relações: as redes sociais e sua influência na atividade fisioterápica}

A formação de um novo negócio pode estar associada às influências dos relacionamentos pessoais do empreendedor. Assim, as relações sociais no ambiente de negócio acontecem entre indivíduos ou entre pessoas de duas ou mais organizações (GRANOVETTER, 1992). Antes de tomar uma decisão sobre o empreendimento os indivíduos, muitas vezes, recorrem às suas redes de relacionamento construídas nas interações sociais presentes na trajetória de vida. Essa rede de relações, que abrange os contatos familiares, acadêmicos e sociais, pode influenciar na definição do caminho a ser seguido em um determinado negócio.

No exame das entrevistas constatou-se a influência predominante de dois tipos de relações sociais nos serviços de fisioterapia: as familiares e as acadêmicas. As relações 
familiares se evidenciam em dois momentos: no período de formação e na etapa que precede à decisão pelo negócio a ser constituído. Em ambos períodos a presença paterna é ressaltada na forma de aconselhamento, referência profissional e apoio financeiro e afetivo. Observou-se, em escala menor, situações de depoentes que declararam não terem sido influenciados pelas relações familiares na escolha subseqüente do negócio.

O sistema de relações engloba também as amizades com companheiros de trabalho ou de escola. Pela análise dos dados evidenciamos que essa dimensão se concentrou quase que exclusivamente no meio acadêmico, em especial, com colegas ou professores da área. As relações com contemporâneos de formação acadêmica auxiliam na construção de visões conjuntas que muitas vezes posteriormente se transformam em negócios empreendedores. A consolidação de empreendimentos se mostrou mais efetiva nas interações sociais mantidas com os professores durante o curso:

“[...] a professora solicitou voluntários para estar atuando num projeto de extensão num asilo. Eu fui voluntária, fui selecionada e trabalhei lá. A partir daí eu me engrenei na geriatria, fiz o trabalho de conclusão de curso com a professora, depois eu fiz o curso de especialização na UFMG, onde a professora também dava aula. Com certeza, eu encontrei uma pessoa que me influenciou, eu me espelhei nela, então eu acho que foi um impulso a mais" (Professor 01).

“[...] tive muita influência também dos professores durante a faculdade. Eles me ajudaram tanto que eu consegui muita coisa na área de respiratória. Se eu quisesse continuar trabalhando, eu estaria trabalhando ainda em outro hospital" (Inicial Novo $05)$.

“O dono da clínica era um professor que me auxiliou muito; com quem eu aprendi a parte técnica da fisioterapia, o professor e a esposa dele. Ela foi a minha orientadora de mestrado e sempre me estimulou muito, não só a estudar, como também ter uma vida clínica, porque é da prática clínica que a gente tem as dúvidas para estudar no mestrado, na academia. Essas pessoas me auxiliaram muito no meu crescimento profissional, na parte técnica e na parte administrativa" (Professor 05).

As relações com docentes possibilitaram nortear alguns dos empreendimentos analisados, tanto na formação posterior em docência (Professor 01), como na escolha da especialização (Inicial Novo 05) e na abertura e desenvolvimento de negócios (Professor 05). Os relatos demonstram ser o ambiente acadêmico um local profícuo para a visualização e consolidação de ações empreendedoras na área fisioterápica.

Pelos núcleos de sentido extraídos do tema sistema de relações sociais evidenciou-se momentos nos quais os profissionais fisioterapeutas empregaram contatos de atividades laborais exercidas antes da opção pelo atual empreendimento. Essas relações secundárias externas (FILLION, 1991) foram facilitadas por redes de relacionamentos cultuadas no meio social, em entidades de classes e em interações com outros profissionais do segmento fisioterápico:

“[...] eu tive alguns amigos que me indicavam pacientes assim que me formei ou me indicavam uma academia que estava precisando de um fisioterapeuta. Além disso, as pessoas com que quem eu trabalhava me influenciaram muito no sentido do que fazer, de indicações, de falar, de me indicar para eu estar numa atividade, para eu estar fazendo alguma coisa" (Outros 04).

“[...] eu participo de algumas listas de discussão pela Internet como, por exemplo, da Associação Mineira de Fisioterapia Esportiva. Agora entrei na Sociedade Nacional de Fisioterapia Esportiva, exatamente para estabelecer bons relacionamentos e daí crescer mais ainda profissionalmente" (Outros 09). 
"Eu fui com o meu marido na época, ele foi fazer um curso na Alemanha. Procurei o hospital no qual esse livro era baseado [mostrando o livro], e ai o quê que aconteceu? Eu conheci os neo terapeutas que atendiam nesse hospital, nessa maternidade, e eles faziam esse trabalho muito bonito logo depois do parto, durante a gravidez, foi quando eu voltei pro Brasil e resolvi de peito aberto implantar esse serviço." (Estabelecido 05)

As influências acima manifestadas advêm de relações sociais externas, de relacionamentos originados de atividades que serviram de base para a construção visionária do negócio e para o seu próprio aprimoramento. A área da fisioterapia, como qualquer outra das ciências da saúde, envolve o aprofundamento das relações pessoais terapeuta-paciente, que se reverte também para um criterioso processo de seleção da rede de pessoas responsáveis pela prestação do serviço. O condutor do negócio elabora estratégias para estruturar seu sistema de relações sociais internas tendo como referência critérios de confiabilidade, comprometimento e competência profissional. Os depoimentos que se seguem revelam como as indicações da rede de relacionamentos, a dedicação e a experiência profissional interferem na estruturação da rede interna no serviço fisioterápico:

\begin{abstract}
"Eu tenho alguns critérios: eu primeiro sigo a indicação de alguém, depois vejo a questão da empatia. Outro fator importante é saber se o outro é bom de serviço. Graças a Deus, eu estou com uma equipe excelente. São pessoas que, às vezes, fizeram o curso [de cuidador de idosos], eu fico observando, sou muito observadora neste aspecto" (Inicial Nascente 01).
\end{abstract}

"Na empresa, eu acho que o critério que existe aqui seria compromisso. Se eu vejo que é uma pessoa de compromisso, que ela está engajada no nosso trabalho, em fazer a clínica crescer, esta pessoa vai estar junto comigo em tudo. Mas, se eu vejo que é uma pessoa não engajada, eu não vou insistir, não vou colocar no meu círculo de relações, nos meus negócios. Por exemplo, em alguns empreendimentos, se eu vejo que essa pessoa não é uma pessoa interessada, ela não entra, eu simplesmente vou excluir" (Estabelecido 04).

“[...] eu vejo quem trabalha bem. Por exemplo, a gente precisou de uma massagista para trabalhar com a gente, contratei uma que eu já fazia massagem com ela, ela trabalha bem, ela é profissional. Para contratar os fisioterapeutas que trabalham com a gente o critério é o mesmo. A indicação de amigos da faculdade que a gente tinha, que sabiam o que a gente falava: 'esse vai dar um excelente profissional', 'esse a gente sabe que não vai ser tão bom', 'esse não vou trabalhar com ele', 'esse não vou indicar"” (Inicial Novo 05).

O critério da indicação como fator de ampliação da rede interna de relacionamento remete aos laços de confiança existentes com a pessoa que sugere a contratação de um novo integrante para o empreendimento. Paralelo à confiabilidade que permeia esse processo estabelece-se algumas condições para receber o componente e mecanismos que avaliem os níveis de idoneidade, comprometimento e empenho do pretendente.

A construção do sistema de relações pressupõe também objetivos de cunho comercial. $\mathrm{O}$ intimismo que marca as relações fisioterapeuta-paciente acaba, muitas vezes, tornando-se um multiplicador da clientela. Como explica o depoente abaixo, isso ocorre quando o fisioterapeuta passa a fazer parte da rede de relações do paciente:

"Tem alguns critérios, por exemplo, relacionamentos com médico, pessoas que te encaminham pacientes. A forma como você atende o seu cliente, como você explica para o seu cliente, é uma forma de se manter um relacionamento com ele e fazer com que ele te encaminhe também outros pacientes, isso sempre teve na minha cabeça. Eu sempre pensei assim e ajo assim. Isso me traz um retorno. Quanto mais 
seguro ele sente com você, ele vai te encaminhar outros clientes, então essas são coisas importantes do relacionamento inter-pessoal" (Professor 04).

Conforme visto neste tópico a rede de relações no meio fisioterápico auxilia na construção da visão, na edificação do negócio e na sua ampliação. No início do empreendimento a interação com familiares é realizada com o propósito de orientação, transferência de experiências e, no caso de famílias com melhores condições financeiras, de capitalização do negócio.

Pelas entrevistas foi possível perceber que as relações acadêmicas, em termos dos colegas de formação, funcionaram como fatores propulsores de idéias para novos negócios. Por sua vez, contatos mais efetivos com professores ajudam na aquisição de conhecimentos da área profissional e na definição de nichos de serviços ainda não explorados. Em relação aos sistemas internos de relações, as indicações e as formas de avaliação do potencial dos futuros componentes da rede social compõem as estratégias mais utilizadas pelos condutores dos negócios.

\section{CONCLUSÕES}

O objetivo principal desse estudo foi analisar a influência das competências empreendedoras e das redes de relações sociais do fisioterapeuta na escolha do negócio ou atividade a ser desenvolvido na área fisioterápica Pelos depoimentos foi possível entender como o desenvolvimento das competências individuais e dos sistemas de relações influenciam na decisão de empreender do fisioterapeuta.

$\mathrm{Na}$ fase que antecede a escolha da atividade fisioterápica a ser empreendida, as competências são desenvolvidas no ambiente acadêmico e organizacional. Entre as competências associadas à visão do ambiente, cabe destacar o desenvolvimento de habilidades especialistas e aquelas obtidas por meio da experiência profissional. Em relação ao mercado, o fisioterapeuta desenvolve competências relacionadas a visualizar oportunidades de demandas de serviços organizacionais ou relativas a um segmento social específico.

Mais do que agir de forma planejada, a maioria dos entrevistados decidem intuitivamente no processo de escolha da atividade a ser empreendida. Isto pode ser observado pela não utilização de fontes de informação preliminares que amparem a opção profissional. Uma das possíveis explicações para essa ausência de investigação sobre os fatores externos que afetam o empreendimento pode estar associada à própria formação dos cursos de fisioterapia, que não aprofundam em disciplinas ligadas ao empreendedorismo, ao planejamento e à gestão organizacional. A ação intuitiva prevalece também após a abertura do negócio, na maioria das vezes enfrentado com a "cara e a coragem" respondendo aos problemas, à "medida em que eles aparecem".

As competências associadas à ação estratégica dizem respeito a se antecipar ao mercado e oferecer serviços pioneiros e diferenciados. No decorrer desses processos criativos, a diversificação de serviços pode representar um diferencial em relação aos concorrentes. Ambiente de trabalho, recursos tecnológicos e forma de atendimento representam elementos da estrutura do negócio que quando bem utilizados asseguram a qualidade de execução do processo estratégico.

As competências relacionadas a diferenciar no atendimento aos clientes são evidenciadas na concepção de modelos de capacitação de pessoal e na própria criatividade expressada para atrair e manter a demanda do serviço. Em termos dos profissionais que atuam na área de formação acadêmica, as atividades de qualificação se traduzem em diferenciais estratégicos desses docentes. 
As redes de relações, em especial, familiar e acadêmica, exercem forte influência na decisão profissional do fisioterapeuta nos períodos que antecedem a formação e a opção pelo tipo de serviço a ser prestado. As influências familiares predominam no início do empreendimento, derivadas principalmente da orientação e apoio financeiro prestado pelos pais. Já as relações acadêmicas originadas de contato com professores e colegas de curso, exercem influência na constituição e manutenção do empreendimento.

O sistema de relações sociais envolve também interações com finalidades de crescimento e proliferação do negócio. Internamente, o fisioterapeuta seleciona a rede de profissionais com que atuará. Os relacionamentos com outros profissionais da área de saúde acontecem no sentido de impulsionar a procura pelos serviços e possibilitar o fluxo de indicações de clientes. O estreitamento das relações com o paciente permite também o aumento da escala de atendimentos decorrente da qualidade do serviço prestado.

Uma das contribuições desse estudo está na possibilidade de replicação da pesquisa para outras profissões que envolvem a abertura de negócio próprio. $\mathrm{O}$ modelo epistemológico proposto, que sugere analisar as competências e a influência das interações sociais nas perspectivas da percepção do ambiente e da ação estratégica, pode vir a auxiliar na investigação da dinâmica desses dois construtos em outras atividades de natureza empreendedora, como odontologia, advocacia, veterinária e outras. Sugere-se também como estudos futuros a realização de pesquisas quantitativas que mensurem as relações de influência entre os atributos investigados: competências empreendedoras e sistemas de relações.

\section{REFERÊNCIAS:}

ALDRICH, H.; ZIMMER, C. Entrepreneurship through social networks. In: SEXTON, D.; SMILOR, R. (Org.). The Art and Science of Entrepreneurship. Cambridge, MA: Ballinger Publishing, 1986. cap. 1.

BARDIN, L. Análise de Conteúdo. Lisboa: Edições 70, 1979.

BARNIR. A.; SMITH, K. Interfirm alliances in the small business: the role of social network. Journal of Small Business Management, Morgantown, W.Va., v. 40, n. 3, p. 219-232, July 2002.

BENEDETTI, M. H. et al. As necessidades de auto-realização e a motivação do empreendedor: uma análise de empreendedores de micro e pequenas empresas da região de Barueri. Brasília: EnANPAD, 2005.

BERGAMINI, C.W. Motivação nas organizações. 4. ed., São Paulo: Atlas, 1997.

BERNARDI, L. A. Manual de empreendedorismo e gestão: fundamentos, estratégias e dinâmicas. São Paulo: Atlas, 2003.

BIRLEY, S. The role of networks in the entrepreuneurship process. Journal of Business

Venturing, New York, v. 1, p. 107-117, Winter, 1986.

BRUSH, C. G.; GREENE. P.G.; HART, M. M. From initial idea to unique advantage: the entrepreneurial challenge of constructing a resource base. Academy of Management Executive, v. 15, n.1, p. 64-80, 2001.

DACIN, M. T.; VENTRESCA, M. J.; BEAL, B. D. The embeddedness of organizations: dialogue and directions. Journal of Management, v. 25, n. 3, p. 317-356, 1999.

DEGEN, R. O empreendedor: fundamentos da iniciativa empresarial. São Paulo: McGrawHill, 1989.

DESCHAMPS, J.; NAYAK, P. Produtos irresistíveis. São Paulo: Makron Books, 1996.

DORNELAS, J. C. A. Empreendedorismo: transformando idéias em negócios. 2. ed. rev. e atual. Rio de Janeiro: Elsevier, 2005. 
DRUCKER, P. F. Inovação e espírito empreendedor. 2. ed., São Paulo: Pioneira Thomson, 1986.

FILION, L. J. O planejamento do seu sistema de aprendizagem empresarial: identifique uma visão e avalie o seu sistema de relações. Revista de Administração de Empresas Fundação Getúlio Vargas. São Paulo, jul./set. 1991.

Visão e Relações: elementos para um metamodelo empreendedor. Revista de

Administração de Empresas - Fundação Getúlio Vargas. São Paulo, nov./dez. 1993.

Diferenças entre Sistemas Gerenciais de Empreendedores e Operadores de

Pequenos Negócios. Revista de Administração da USP. São Paulo, v. 39, n. 4, p. 1999a.

. Empreendedorismo: empreendedores e proprietários gerentes de pequenos negócios.

Revista de Administração de Empresas. São Paulo, v. 34, n. 4, p. 5-28, abr./jun. 1999b.

FLEURY, A.; FLEURY, M. T. L. Estratégias empresariais e formação de competências:

um quebra-cabeça caleidoscópio da industria brasileira. 3. ed. São Paulo: Atlas, 2004.

GEM - Global Entrepreneuship Monitor. Report Summary, 2007. Informações disponíveis no site: http://www.gemconsortium.org.

GRANOVETTER, M. Economic action and social structure: the problem of embeddedness.

American Journal of Sociology. Chicago, v. 91, n.3, p. 481-510, nov. 1985.

Problems of explanation in economic sociology. IN: NOHRIA, N.

ECCLES, R. G. (Org.). Networks and organizations: structure, form, and action. Boston:

Harvard Business School Press, Cap.1, p. 25-26, 1992.

JOHANNISSON, B. Personal networks in emerging knowledge-based firms: spatial and functional patterns. Entrepreneurship and Regional Development, v. 10, n. 4, p. 297-312, oct./dez.1998.

KETS DE VRIES, M. F. R. The anatomy of the entrepreneur: clinical observations. Human Relations, v. 49, n. 7, 1996.

KURATKO, D. F. HODGETTS, R. M. Entrepreneurship: Theory, Process, Practice. South-Western/Thomson Publishers, 2004.

LARSON, A. Partner networks: leveraging external ties to improve entrepreneurial performance. Journal of Business Venturing, New York, v. 6, n. 3. p. 173-188, May 1991.

Network dyads in entrepreunrial settings: a study of the governance of exchange

relationships. Administrative Science Quarterly, Ithaca, v. 37, p. 76-104, March. 1992.

LILES P. R. New Business Ventures and the Entrepreneur. Homewood, IL: Irwin, 1974

LYLES, M. A. et al. Formalized planning in small business: increasing strategic choices. Journal of Small Business Management. April, 1993, p. 38-50.

LUZ T. R. Estratégias competitivas e competências. In: RODRIGUES S.B.; CARRIERI A P.; LUZ, T. R. Tempos de desconstrução: evolução e transformação nas empresas: um estudo de uma empresa de telefonia. Belo Horizonte: UFMG/FACE/CEPEAD, 2003.

MAN, T. W. Y.; LAU, T. Entrepreneurial competencies of SME owner/manager in the Hong Kong services sector: a qualitative analysis. Journal of Entreprising Culture, v. 8, n. 3, 2000.

MICHAELIS: O Moderno Dicionário da Língua Portuguesa. São Paulo: Melhoramentos, 2004.

MINAYO M. C. S. O Desafio do conhecimento: pesquisa qualitativa em saúde, 9. ed. revisada, São Paulo: Hucitec, 2006.

OSTGAARD, T. A.; BIRLEY, S. Personal networks and firm competitive strategy - A strategic or coincidental match? Journal of Business Venturing, New York, v. 9, n. 4, p. 281-305, July 1994.

PAIVA JR. F. G. O. et al. Competências Empreendedoras em Comportamentos de Dirigentes de Exxito Socialmente Reconhecido. EnANPAD. São Paulo, 2003.

PAIVA, JR. F. G. O. et al. A contribuição das competências empreendedoras para a formação de dirigentes em sistemas de incubação. XXVI ENEGEP - Fortaleza, CE, Brasil, 9 a 11 out. 2006. 
PARDINI, D. J. A formação cultural como construto de ligação entre visão empreendedora e ação estratégica - uma análise do caso da USIMINAS. 3 ES - II Encontro de Estudos em Estratégia. Rio de Janeiro, 08 a 10 de junho de 2005.

VAN GIGCH, J.P. Decision making about decision making: metamodels and metasystems. Cambridge: Mas and Tunbridge Wells, Kent, Abacus Press, 1987.

VASCONCELOS, G. M. R. Inserção Social e Recursos: um estudo de caso comparativo da criação e desenvolvimento de novos negócios. Revista de Administração de Empresas. Brasília, RAE FGV, 2005.

WEBSTER DICTIONARY. Barnes \& Noble Books, 1999.

WHITING, B. G. Creativity and entrepreneurship: how do they relate? Journal of Creative Behaviour, 22, n. 3, 1988, p. 178-183. 